\title{
On the Impact of the Financial Crisis on the Dividend Policy of the European Insurance Industry
}

\author{
Sebastian Reddemann ${ }^{\mathrm{a}}$, Tobias Basse ${ }^{\mathrm{b}}$ and Johann-Matthias \\ Graf von der Schulenburg ${ }^{\mathrm{c}}$ \\ ${ }^{a}$ Center for Risk and Insurance, Leibniz Universität Hannover, Königsworther Platz 1, \\ Hannover D-30167, Germany \\ ${ }^{\mathrm{b}}$ Norddeutsche Landesbank (NORD/LB), Friedrichswall 10, Hannover D-30159, Germany. \\ ${ }^{\mathrm{c} I n s t i t u t e ~ f o r ~ R i s k ~ a n d ~ I n s u r a n c e, ~ L e i b n i z ~ U n i v e r s i t a ̈ t ~ H a n n o v e r, ~ K o ̈ n i g s w o r t h e r ~ P l a t z ~ 1, ~}$ \\ Hannover D-30167, Germany
}

The financial crisis has led to controversial discussions about the capital base of the European insurance industry. Dividend cuts have been suggested to preserve capital. However, some observers seem to fear that investors could interpret a reduction of dividends as a sign of future problems. The empirical evidence reported here does not indicate that dividend smoothing or dividend signalling are relevant economic phenomena examining the dividend policy of the European insurance industry. Therefore, insurance companies should not be too concerned about the negative consequences of dividend cuts. The Geneva Papers (2010) 35, 53-62. doi:10.1057/gpp.2009.37

Keywords: capital base; dividend policy; smoothing; signalling; financial crisis

\section{Introduction}

The subprime mortgage crisis and its negative effects on capital markets and global economic growth have shattered the financial sector as a whole. Obviously, banks have had to bear the brunt of the crisis. Nevertheless, stock prices of many insurers also have at least temporarily plummeted. In this difficult situation a number of European insurance companies have debated on either capital increases or dividend cuts in order to preserve capital anticipating further write downs or even to comply with minimum capital requirements demanded by regulation. Improving their capitalization and financial strength may be necessary to stabilize the credit ratings of some insurers, avoiding possible downgrades by the rating agencies. Additional pressure may be imposed by the regulators, as there are discussions to react to the crisis by increasing capital requirements not only for banks. Bullard, Neely and Wheelock, for example, recently discussed several proposals of new government regulations laying a special focus on the American International Group (AIG). ${ }^{1}$ Even prior to its full implementation Solvency II may already stimulate the demand for additional capital in the European insurance industry. ${ }^{2}$ However, raising capital from

\footnotetext{
${ }^{1}$ Bullard et al. (2009).

${ }^{2}$ Basse and Friedrich (2008).
} 
external sources may be difficult for insurers. This is also a direct consequence of the crisis as numerous international banks already have issued new equity leading to a shortage of additional capital for financial institutions. Meanwhile stock prices have at least partly recovered. The German Prime Insurance Performance Index, for example, has risen more than 70 per cent from its lowest in 2009. Nevertheless, raising capital could still prove to be expensive for insurance companies in the near future.

Therefore, a dividend cut is the option to strengthen the capital base of the European insurance industry this paper deals with. It is assumed to be an appropriate response to liquidity problems and thus a valid tool in the environment of a financial crisis. As a matter of fact, the level of dividends paid by insurers has dropped by nearly 60 per cent in Europe, in the wake of a trend turning out to be the largest cuts since 1938 throughout all economic sectors according to Standard \& Poor's. ${ }^{3}$ But dividend cuts could be perceived as a negative signal indicating future problems to investors. Given these discussions, this paper plans to empirically analyse the dividend policy issue from the perspective of the European insurance industry, evaluating if dividend cuts may be conducted. The impact of dividend policy on the company's future earnings is evaluated by seeking for dividend smoothing respectively signalling via two econometric approaches while including inflation. If no evidence supporting one of those hypotheses can be found insurers may cut their dividends to strengthen their capital base without necessarily sending a negative signal.

\section{Dividend policy issues and the insurance sector}

In their seminal paper Miller and Modigliani have argued that a firm's dividend policy is irrelevant under certain assumptions. ${ }^{4}$ Most importantly, capital markets are assumed to be perfect and no taxes exist. Under these conditions and with a given investment policy of the firm, higher dividends result in lower capital gains. Therefore, dividend policy has no economic relevance when investors do not prefer dividends to capital gains or vice versa. Accepting this point of view, there is a dividend puzzle because it can be observed that numerous firms in many countries regularly do pay dividends. Trying to solve this dividend puzzle is an important task of financial economics.

Many explanations for the existences of dividend payments are based on agency theory. It is, for example, quite common to argue that dividends reduce free cash flow and thereby force the firms to obtain capital from external sources more frequently when trying to finance new investment projects. This mechanism provides additional external monitoring and thus reduces agency costs. Rozeff has empirically tested explanations of dividend payments based on agency theory examining U.S. data, but has neglected regulated industries (e. g. insurers and banks) in his analysis, arguing that the financing policies of regulated firms may be affected by their special status. ${ }^{5}$ More recently Casey, Smith and Puleo have tested an extend version of Rozeff's model

\footnotetext{
${ }^{3}$ Mackenzie and Oakley (2009).

${ }^{4}$ Miller and Modigliani (1961).

5 Rozeff (1982).
} 
concluding that insurers do not have to employ strong external monitoring by paying high dividends, as this function is executed by the regulators. ${ }^{6}$ Thus Rozeff's explanation of dividend payments is neglected in this paper as dividend cuts are discussed as a measure to improve financial stability in troubled times. Many observers do argue that capital is scarce following a major financial crisis that is sometimes even compared to the Great Depression. In fact, as a result of numerous international banks issuing new equity there is a shortage of additional capital for financial institutions rendering the agency theory useless, as the monitoring function cannot be upheld due to market constraints. Therefore, other explanations of dividend policy have to be examined.

Economic theory does suggest that the management of a firm may use dividend changes to overcome information asymmetries by signalling revisions to earnings expectations to current and prospective investors. This is the so-called signalling hypothesis of dividend policy. To avoid investors misinterpreting the management's actions, it may be reluctant to cut dividend payments. Accepting this point of view has a number of consequences for the process of dividend signalling. Most importantly, according to this view dividends should only be increased when management believes that future cash flows are sufficiently strong and enable the firm to sustain the new higher level of dividend payouts. Consequently this second theory, called the dividend smoothing hypothesis, which may be seen as precautious signalling, does also assume that a strong link between dividend payments and corporate earnings exists. However, Goddard, McMillan and Wilson have argued convincingly that the signalling and smoothing hypotheses make opposite predictions about the temporal relationship between dividends and corporate earnings. ${ }^{7}$ While the signalling hypothesis predicts that dividends lead earnings, the smoothing hypothesis suggests that earnings lead dividend payments. In econometrics and more generally in empirical research the question of causality is ambiguous. Here two approaches to this question are followed, namely the concept of Granger causality and the even stronger one of impulseresponse analysis. The procedures are further explained in the next section.

Dividend policy is usually discussed from the perspective of industrial firms. An extensive survey of this literature has been presented by Allen and Michaely. ${ }^{8}$ However, only few researchers have focused on dividend policy issues with respect to insurance companies. Meanwhile, research with this special focus seems to become increasingly popular. Recently, He and Liang, for example, have modelled the optimal financing and dividend payout strategy of insurance companies assuming that the management of the firm can control dividend policy, equity issuance and the reinsurance rate. ${ }^{9}$

Insurers are often regarded as special because industrialized economies do very much depend on the financial soundness of the insurance sector. Therefore, the insurance industry in Europe and other parts of the world is subject to very tight

\footnotetext{
${ }^{6}$ Casey et al. (2009).

${ }^{7}$ Goddard et al. (2006).

${ }^{8}$ Allen and Michaely (1995).

${ }^{9} \mathrm{He}$ and Liang (2009).
} 
government regulation. Obviously, the primary goal of insurance regulation is to guarantee the solvency of insurance companies. As stated previously, Casey, Smith and Puleo have shown that agency costs are not a major factor in strongly regulated markets. ${ }^{10}$ So why do insurance companies pay dividends at all? In a second study, Casey, Smith and Puleo have argued that investors probably prefer a high degree of leverage in the insurance sector (while complying with regulation) since not just customers but also investors are protected against insolvency by regulators. ${ }^{11}$ According to this hypothesis, investors can use dividend income from insurers to obtain other financial assets and maintain a high level of relatively risk-free leverage, holding a more or less constant amount of funds invested in their portfolio of insurance stocks.

Examining the U.S. property and liability insurance industry by explaining the monthly returns of 34 insurance stocks by the Capital Asset Pricing Model (CAPM) beta and their dividend payouts, Lee and Forbes have documented some empirical evidence indicating that dividend policy does have effects on stock prices of insurance companies. ${ }^{12}$ Akhigbe, Borde and Madura have further refined these findings using crosssectional event studies to compare the stock price response to dividend increases. ${ }^{13}$ They find that dividend changes of insurance companies are perceived differently to industrial firms with the special case of life insurers conveying less asymmetric information than those of other insurers as the stock price response to dividend changes was less. This means investors could be interested in non-public information about future cash flows. As a consequence, dividend signalling may have a special importance in the non-life insurance industry. Therefore, investors may have mixed feelings about dividend increases of life insurers because a higher volume of dividend payments reflects a smaller contribution to capital. This kind of reasoning does have some tradition. In his study of the dividend policy of U.S. life insurers Harrington has already argued that high dividend payouts can weaken the financial soundness of insurance companies. ${ }^{14}$ Moreover, Akhigbe, Borde and Madura have also noted that the regulation of life insurers could force more public disclosure of information than is available from industrial firms reducing the need for dividend signalling. ${ }^{15}$ This argument becomes even more striking within the Solvency II framework and its tightened disclosure requirements for insurance companies.

\section{Data and methodology}

After reviewing the recent empirical evidence on dividend policy, Bhattacharyya has argued that properly conducted empirical research should account for all implications

\footnotetext{
${ }^{10}$ Casey et al. (2009).

${ }^{11}$ Casey et al. (2007).

${ }^{12}$ Lee and Forbes (1980).

13 Akhigbe et al. (1993).

${ }^{14}$ Harrington (1981).

15 Akhigbe et al. (1993).
} 
of the respective underlying economic theories. ${ }^{16}$ Given that there are numerous factors affecting a firm's dividend policy, this is difficult to achieve. Basse, for example, has recently noted that inflation may have an effect on dividend payments analysing the dividend policy of Australian firms. ${ }^{17}$ However, inflation is generally neglected in empirical work examining dividend policy issues - though Modigliani has noted that the earnings-payout ratio is increased by inflation while stock prices might not change due to different leverage of those effects. ${ }^{18}$ Therefore, this article also focuses on the aspect of inflation studying the dividend policy of the European insurance industry.

As a consequence, this study takes a more macroeconomic perspective, analysing the dividend policy of German and European (or - to be more precise - the European Monetary Union (EMU)) insurance companies by examining quarterly data on earnings and dividends reported for the insurance sector indices of the Deutsche Börse Prime All Share Index and the Dow Jones Euro Stoxx stock market indices while also considering inflation. More specifically, the dividend per index share and earnings per index share data provided by Bloomberg are used. Inflation is measured by the GDP price deflator of the respective economic area. Obviously analyses on the more aggregate level of indices have their shortcomings, but the data for individual insurers are heterogeneous and often incomplete. Thus these two indices are adequate proxies for the dividend and earnings levels throughout the insurance sector. Trying to avoid possible problems due to the introduction of the Euro, the sample analysed contains 1999 Q1 to 2008 Q4.

To identify the conjectured causalities between earnings and dividends, two different concepts are used. First of all it is tested for Granger causality, meaning the knowledge of one of the variables is significantly improving the forecast of the other. After that impulseresponse techniques in the Vector-Error-Correction Model (VECM) environment are applied to analyse the interdependencies among the three variables, searching for signs of dividend signalling or dividend smoothing. This is accomplished by performing an impulse-response analysis, observing two time series after shocking the third, deducing the causal structure between these three time series. Finding no empirical evidence supporting one of these two theories of dividend determination would imply that insurers have until now not been forced to maintain a somehow stable lead-lag relationship between dividends and earnings. This result would indicate that insurance companies may cut dividends to improve their financial soundness without necessarily having to fear major negative consequences. On the other hand, empirical evidence indicating that dividend signalling or dividend smoothing have been relevant economic phenomena would imply that cutting dividends actually has negative consequences.

\section{Results}

As proposed standard Granger causality tests are performed for the two described differentiated datasets (these are non-stationary time series as indicated by not reported Augmented Dickey-Fuller (ADF) tests), yielding the following results (Tables 1 and 2).

\footnotetext{
${ }^{16}$ Bhattacharyya (2007).

${ }^{17}$ Basse (2009).

${ }^{18}$ Modigliani (1982).
} 
Table 1 Granger causality: Germany

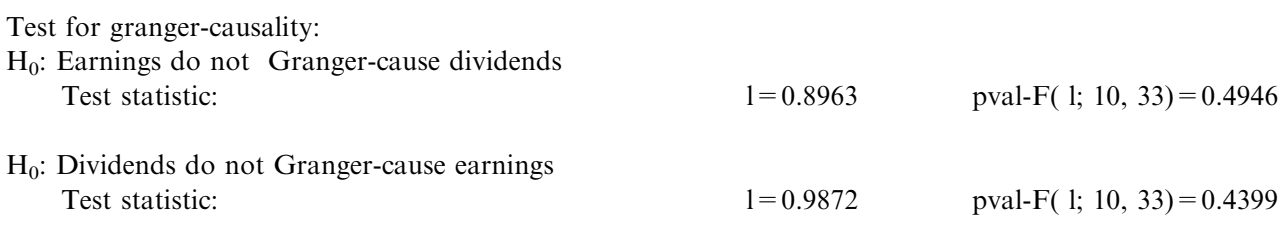

Table 2 Granger causality: Europe

Test for granger-causality:

$\mathrm{H}_{0}$ : Earnings do not Granger-cause dividends

Test statistic:

$1=2.9429$

pval-F $(1 ; 10,36)=0.0236$

$\mathrm{H}_{0}$ : Dividends do not Granger-cause earnings

Test statistic:

$1=0.9838$

pval-F $(1 ; 10,36)=0.4396$

These results mean the Null-hypothesis of no Granger causality cannot be omitted for Germany in both directions and from Dividends to Earnings in the EMU. Only the hypothesis of Earnings not Granger-causing Dividends has to be dropped, giving a hint at the validity of dividend smoothing, at least on the level of the EMU insurance industry. These first results will now be tested using the more sophisticated framework of impulse-response analysis of a VECM. This model class includes long-term equilibria between variables in a standard VAR by adding this link in the regression equation to be estimated. Thus this technique considers interdependencies not accounted for in standard multi time-series models. Some preliminary standard tests have to be conducted to fix the parameters and to validate the applicability of this model class.

As mentioned, ADF tests suggested all six time series examined are non-stationary and integrated of order one as needed by a VECM. Furthermore, testing for cointegration is required. The test of Johansen ${ }^{19}$ is applied in this case yielding the following results for Germany (Table 3), using the critical values for breakpoint scenarios from Johansen, Mosconi and Nielsen. ${ }^{20}$

Seasonal dummies are included to account for the strong seasonal patterns induced by the dividends. Furthermore, a breakpoint in the test is included in $2001 \mathrm{Q} 4$, as a massive shift in earnings due to the events surrounding the terrorist attacks on 9-11 is observed. The questions surrounding terror insurance are dealt with in great depth in a paper by Thomann and Schulenburg. ${ }^{21}$ The dividend cuts in that period were not as serious as the ones occurring right now, due to the nature of the incident being different from the inherent problems the financial sector has to deal with in the current crisis. Thus both periods (pre 9-11 and post 9-11) have to be analysed separately.

\footnotetext{
19 Johansen (1991).

${ }^{20}$ Johansen et al. (2000).

${ }^{21}$ Thomann and von der Schulenburg (2007).
} 
Table 3 Cointegration between earnings, dividends and inflation in Germany

\begin{tabular}{lccccr}
\hline \multicolumn{7}{c}{ Trace test (seasonal dummies included) } \\
\hline Hypothesized no. of $C E(s)$ & LR & Pval & $90 \%$ & $95 \%$ & $99 \%$ \\
\hline 0 & 67.48 & 0.0000 & 38.91 & 41.69 & 47.25 \\
1 & 32.20 & 0.0039 & 22.83 & 25.09 & 29.73 \\
2 & 7.89 & 0.2572 & 10.66 & 12.50 & 16.46 \\
\hline
\end{tabular}

\section{VECM Orthogonal Impulse Responses}
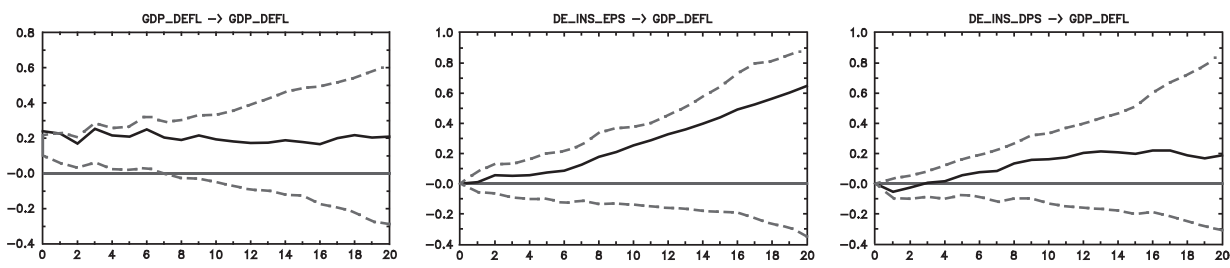

GDP_DERL $\rightarrow$ DEEINS_EPS
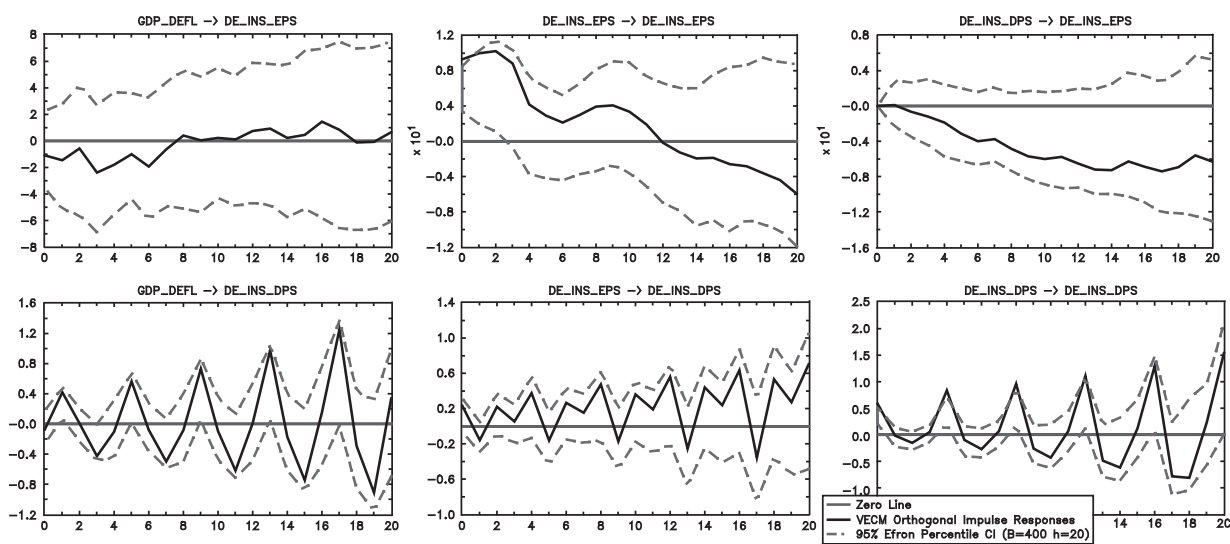

Figure 1. Impulse-response analysis: Germany.

The cointegration test provides evidence for the existence of two cointegration relationships, meaning the VAR should be augmented by a linear combination of the original variables. While estimating this VECM with the three variables inflation (DE_GDP_DEFL), earnings (DE_INS_EPS) and dividends (DE_INS_DPS) the rank of cointegration is therefore assumed to be two. Seasonal dummies were included and time lags of up to one year (four quarters) are considered in the process. The resulting impulse-response functions with bootstrapped confidence intervals (400 replications) are displayed below (Figure 1).

Using the Cholesky decomposition to orthogonalize the impulses as suggested by Sims, the ordering of variables follows economic theory. ${ }^{22}$ We assume that inflation is the most exogenous variable and that dividends are paid from earnings. The graphs 
Table 4 Cointegration between earnings, dividends and inflation in Europe

Trace test (seasonal dummies included)

\begin{tabular}{lccccr}
\hline Hypothesized no. of $C E(s)$ & LR & Pval & $90 \%$ & $95 \%$ & $99 \%$ \\
\hline 0 & 63.02 & 0.0000 & 38.84 & 41.55 & 46.97 \\
1 & 25.76 & 0.0397 & 22.83 & 25.06 & 29.60 \\
2 & 7.17 & 0.3297 & 10.74 & 12.57 & 16.52 \\
\hline
\end{tabular}

VECM Orthogonal Impulse Responses
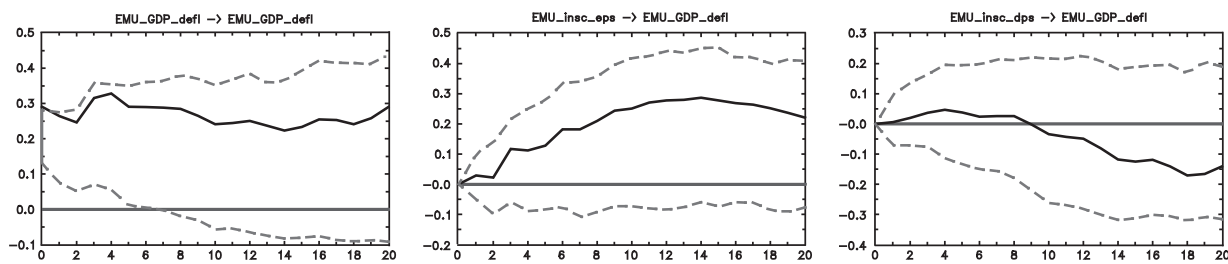

ENU_GDP_dofl $\rightarrow$ EMU_insc_ops

EMU_inso_ops $\rightarrow$ EMU_insc_ops
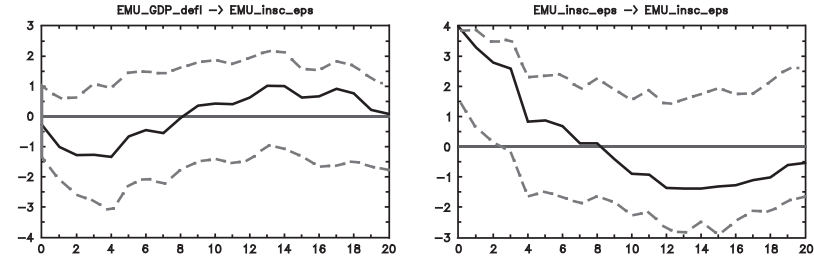

EMU_inso_dps $\rightarrow$ EMU_insc_ope

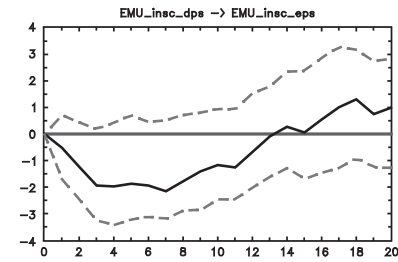

EMU_GDP_defl $\rightarrow$ EMU_insc_dpe

ENU_insc_eps $\rightarrow$ EMU_inso_dps
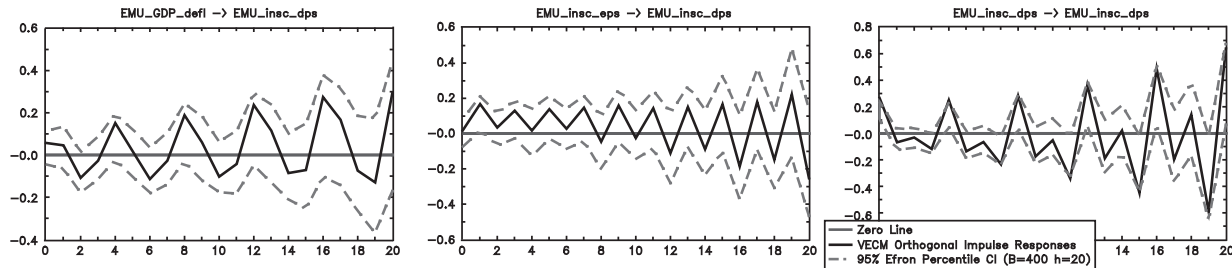

Figure 2. Impulse-response analysis: Europe.

clearly show no significance of dividends to earnings or vice versa, as the confidence intervals do always contain the time-axis, meaning the response is not significantly different from zero. Therefore, following Goddard, McMillan and Wilson no evidence that dividend signalling or dividend smoothing are relevant phenomena could be found. $^{23}$

Now the same techniques are applied to the set of data for the European insurers examining the variables inflation (EMU_GDP_DEFL), earnings (EMU_INS_EPS) and dividends (EMU_INS_DPS). The estimation used four lags (one year) and the breakpoint at 2001 Q4 again. Seasonal dummies were included as well. The results of the cointegration test are presented in Table 4. The respective impulse-response functions are displayed in Figure 2. Again dividends do not react significantly to

${ }^{23}$ Goddard et al. (2006). 
shocks in earnings and vice versa even though the confidence intervals in the Earnings on Dividends graph scrape the zero.

These results do not support the conjecture of causality between earnings and dividends and the result found in the Granger-causality test could not be backed up by the impulse-response analysis. One explanation for the differing outcomes of the analyses is the inability of standard Granger-causality tests to account for the complex relationship among the three variables, which is explicitly used in the impulse-response analysis. Especially the interdependence with inflation is neglected in the standard tests.

\section{Conclusion}

Dividend cuts are one way to improve the capitalization and financial strength of the European insurance industry. This article examines the dividend policy of European and specifically German insurers using VECM techniques. The basic argument is that without any empirical evidence dividends actually did matter in the past, insurers may reduce or even omit dividend payments if needed. The results of the empirical investigations are quite clear. No convincing evidence was found indicating that dividend smoothing or dividend signalling are relevant economic phenomena examining the dividend policy of the European insurance industry. This result does have major implications. Most importantly, facing a severe financial crisis, European insurance companies cutting dividends and thereby improving their financial strength and complying with regulatory standards do not necessarily have to fear major negative consequences due to investors assuming this measure to be an indubitable sign for future problems.

\section{References}

Akhigbe, A., Borde, S.F. and Madura, J. (1993) 'Dividend policy and signaling by insurance companies', Journal of Risk and Insurance 60: 413-425.

Allen, F. and Michaely, R. (1995) 'Dividend policy', in R. Jarrow, V. Maksimovic and W.T. Ziemba (eds) Handbooks in Operations Research and Management Science: Finance, Elsevier, Amsterdam, Vol. 9, pp. 793-837.

Basse, T. (2009) 'Dividend policy and inflation in Australia: Results from cointegration tests', International Journal of Business and Management 4: 13-16.

Basse, T. and Friedrich, M. (2008) 'Solvency II, asset liability management and the European bond market theory and empirical evidence', Zeitschrift für die gesamte Versicherungswissenschaft 97: 155-171.

Bhattacharyya, N. (2007) 'Dividend policy: A review', Managerial Finance 33: 4-13.

Bullard, J., Neely, C.J. and Wheelock, D.C. (2009) 'Systematic risk and the financial crisis: A primer', Federal Reserve Bank of St. Louis Review 91: 403-417.

Casey, K.M., Smith, F.S. and Puleo, V.A. (2007) 'Dividend policy determinants in the insurance industry', Journal of Academy of Business and Economics 7: 178-184.

Casey, K.M., Smith, F.S. and Puleo, V.A. (2009) 'Insurance company dividend policy decisions - Evidence on the role of corporate governance and regulation', Managerial Finance 35: 493-500.

Goddard, J.A., McMillan, D. and Wilson, J.O.S. (2006) 'Dividend smoothing versus dividend signalling: evidence from UK firms', Managerial Finance 32: 493-505.

Harrington, S.E. (1981) 'Stock life insurer shareholder dividend policy and holding company affiliation', Journal of Risk and Insurance 48: 550-576.

He, L. and Liang, Z. (2009) 'Optimal financing and dividend control of the insurance company with fixed and proportional transaction costs', Insurance: Mathematics and Economics 44: 88-94. 
Johansen, S. (1991) 'Estimation and hypothesis testing of cointegration vectors in gaussian vector autoregressive models', Econometrica 59: 1551-1580.

Johansen, S., Mosconi, R. and Nielsen, B. (2000) 'Cointegration analysis in the presence of structural breaks in the deterministic trend', Econometrics Journal 3: 216-249.

Lee, C.F. and Forbes, S.W. (1980) 'Dividend policy, equity value, and cost of capital estimates in the property and liability insurance industry', Journal of Risk and Insurance 47: 205-222.

Mackenzie, M. and Oakley, D. (2009) 'Worst year for dividend cuts since 1938', Financial Times. www.ft.com/cms/s/0/4d750a32-075b-11de-9294-000077b07658.html?nclick_check $=1$.

Miller, M.H. and Modigliani, F. (1961) 'Dividend policy, growth, and the valuation of shares', Journal of Business 34: 411-433.

Modigliani, F. (1982) 'Debt, dividend policy, taxes, inflation and market valuation', Journal of Finance 37: $255-273$.

Rozeff, M.S. (1982) 'Growth, beta, and agency costs as determinants of dividend payout ratios', The Journal of Financial Research 5: 249-259.

Thomann, C. and von der Schulenburg, J.-M.G. (2007) 'Management von Terrorrisiken in Deutschland eine empirische analyse', Zeitschrift für die gesamte Versicherungswissenschaft 96: 271-290.

Sims, C. (1980) 'Macroeconomics and reality', Econometrica 48: 1-48.

\section{About the Authors}

Sebastian Reddemann studied mathematics at Leibniz Universität Hannover. After completing the Math Part III course in Cambridge, U.K., he is now working at the Center for Risk and Insurance of the Leibniz Universität Hannover. He has published in refereed journals. His research interests are financial econometrics, financial math and risk management.

Tobias Basse is an economist working as financial analyst at Norddeutsche Landesbank (NORD/LB) in Hannover. He studied economics and business administration at the universities of Hannover and Paderborn and has published papers on financial economics, insurance economics and monetary economics in numerous peer-reviewed journals.

Johann-Matthias Graf von der Schulenburg studied economics and law in Göttingen. He received his $\mathrm{PhD}$ from the Institute for International Economic Relations at the LMU in Munich. Following one year as assistant professor at Princeton University, he directed the International Institute for Management in Berlin and now leads the Institute for Risk and Insurance at the Leibniz Universität Hannover. He has received numerous awards and has published in major economic and management journals. 